\title{
Passive samplers in sewers and rivers with highly fluctuating micropollutant concentrations - better than we thought
}

Mutzner Lena ${ }^{1,2}$, Vermeirssen Etiënne L. $\mathrm{M}^{3}$, Ort Christoph ${ }^{{ }^{*}}$

1 Eawag, Swiss Federal Institute of Aquatic Science and Technology, 8600 Dübendorf, Switzerland.

2 Institute of Civil, Environmental and Geomatic Engineering, ETH Zürich, 8093 Zurich, Switzerland.

3 Swiss Centre for Applied Ecotoxicology Eawag-EPFL, Überlandstrasse 133, 8600 Dübendorf, Switzerland

*Corresponding author: Eawag, Swiss Federal Institute of Aquatic Science and Technology. Überlandstrasse 133, 8600 Dübendorf, Switzerland.E-mail: christoph.ort@eawag.ch

\section{Abstract}

Considerable pollutant loads can enter surface waters during rain events. Three factors challenge quantification of these pollutant fluxes using traditional sampling methods: (i) concentration fluctuations; (ii) unknown event duration; and (iii) placement, operation, and maintenance of equipment. Passive samplers offer the advantage of sampling in a continuous mode without power supply. However, variable uptake rates due to environmental factors and desorption in the case of fluctuating concentrations can affect the accuracy of time-weighted average (TWA) concentration estimates. While uncertainties related to environmental factors could be accounted for with additional effort, we can neither control nor quantify the concentration variability. We present measured and modelled concentration profiles at high temporal resolution and provide a systematic approach to assessing deviations from true TWA concentration due to fluctuating concentration profiles. We evaluate sampling of sewer overflows $(0.3-14 \mathrm{~h})$ with Chemcatcher and 1-week sampling in rivers. The uncertainty due to fluctuating concentrations is small, and other factors such as chemical analyses and sampler calibration have a similar or higher impact. The uncertainty due to fluctuations clearly increases with the sampling duration, particularly when exceeding the half-life of equilibrium. We conclude that passive sampling can also be used in wastewater systems with potentially high concentration variations.

\section{Keywords}

polar organic pollutant; Chemcatcher; sampling uncertainty; pesticide; pharmaceutical

\section{Abbreviations}

$\mathrm{C}$

$\mathrm{C}_{\mathrm{i}}(\mathrm{t})$

TWA

$\mathrm{C}_{\text {true }}$

PS

M.PS.

$\mathrm{C}_{\mathrm{PS} \text {.meas }}$

$\mathrm{C}_{\mathrm{PS} . \mathrm{mod}}$

$\mathrm{C}_{\text {Comp.Sample }}$
Concentration of contaminant in the water (sewer or river)

Concentration at time point $i$

Time-weighted average

True $\mathrm{C}_{\mathrm{TWA}}$ (based on $\mathrm{C}_{\mathrm{i}}$, no error associated to sampling and measurements)

Passive sampler

Mass of contaminant measured or modelled on passive sampler

$\mathrm{C}_{\mathrm{TWA}}$ measured via passive sampler

$\mathrm{C}_{\text {TWA }}$ modelled for passive sampler

$\mathrm{C}_{\mathrm{TWA}}$ in a composite sample (grab samples combined over a specific sampling period)

\section{Introduction}

The discharge of wastewater, stormwater, and surface runoff from agricultural fields can adversely affect the quality of surface water. Increasingly, the focus is on micropollutants such as pharmaceuticals and pesticides (subsequently referred to as contaminants) that originate from a vast, uncounted number of 
discharge points [1-4]. Therefore, effective sampling of these individual sources and surface waters is of major interest when evaluating and prioritizing further measures to reduce impacts of contaminants. Water concentrations of contaminants discharged from such points into surface waters can fluctuate substantially within short periods of minutes to hours. Concentrations of compounds such as pesticides occurring in runoff have been observed to range over two orders of magnitude or more in flood events [5-7]. These fluctuating concentrations together with event durations that are unknown a priori require high sampling resolutions to cover episodic peaks and thus challenge traditional sampling methods such as grab sampling and automated sampling. One alternative, passive sampling, offers several advantages. One is that a passive sampler is exposed to water continuously during the entire observation period. The mass collected on the passive sampler allows a time-weighted average (TWA) water concentration to be estimated. Various factors are known to influence the reliability of passive sampling results: (i) sampler set-up, installation, and storage; (ii) chemical analysis; (iii) calculation of the water concentration (sampler calibration); (iv) varying environmental conditions such as flow velocity, temperature, and matrix; and (v) fluctuating concentrations. A comprehensive interlaboratory study [8] has shown that both chemical analysis and the calculation of water concentrations are major factors contributing to the overall variation observed among laboratories. Chemical analysis is becoming more accurate. Further, monitoring and reporting of environmental conditions is becoming more common, and performance reference compounds [9] are increasingly studied to minimize uncertainty due to unknown environmental conditions. All these sources of uncertainty need further optimization. However, potentially high fluctuations of contaminant concentrations in water usually remain unknown. Therefore, it is important to quantify the contribution of uncertainty arising from fluctuating concentrations to time-weighted average (TWA) concentration estimates. Previous studies have examined the effect of selected peak events experimentally $[10,11]$ as well as in the field [5, 12-14]. These studies cover all potential uncertainty factors, including uncertainty due to fluctuating concentrations (Figure 1). However, these studies do not allow the effect of fluctuating concentrations to be separated from overall differences observed between passive samplers and composite water samples. Some works study the effect of modelled peaks $[11,15,16]$ or specific patterns [17], thus indicating the uncertainty due to fluctuations of aqueous concentrations. However, these measured and modelled peaks cover just a few selected examples of concentration fluctuations occurring in water systems. We expect that high temporal variations in short periods might contribute substantially to uncertainty, especially in wastewater systems. Therefore, the objective of our study was to systematically quantify the uncertainty in TWA concentration estimates from passive samplers due to concentration fluctuations (\#1 in Figure 1). This was done with novel measured and modelled concentration profiles and compared our uncertainty estimates to other uncertainty factors (\#3 in Figure 1).



Figure 1. Illustration of the approach to determine the uncertainty due to fluctuating concentrations (\#1). Measured and modelled concentrations $\mathrm{C}_{\mathrm{i}}(\mathrm{t})$ at high temporal resolution are used to predict the mass uptake on the sampler disk MPS.mod. The resulting modelled passive sampler TWA concentration $\mathrm{C}_{\mathrm{PS} \text {.mod }}$ is compared with the true TWA concentration $\mathrm{C}_{\text {true }}$ 
We focus on sampling in sewers, and we address three specific aspects:

1. How much uncertainty must be expected from unknown, fluctuating concentration profiles when using a passive sampler to estimate TWA concentrations? We compared concentrations for passive samplers with true TWA ( $\mathrm{C}_{\mathrm{PS} . \bmod } \leftrightarrow \mathrm{C}_{\text {true }}$, sections $2.1 / 2.2$ and 3.1/3.2).

2. How do characteristics of concentration patterns that are typically unknown influence uncertainty? We investigated the effect of event duration, the position of peaks, and the concentration variability (section 2.3 and 3.3).

3. How accurate is a traditional composite sample when measuring fluctuating concentrations? Usually, composite samples are used as a reference ( $\mathrm{C}_{\text {CompSample }} \leftrightarrow \mathrm{C}_{\text {true }}$, section 2.4 and 3.4).

\section{Experimental}

\subsection{Field study: concentration fluctuations in sewers}

The study was conducted at three locations in different sewer systems. An auto-sampler and passive samplers were used simultaneously to monitor one rain event at each location (Figures SI 1-6 for installation setups, Table 2 for event characteristics). At location 1, we sampled in a sewer pipe during wet weather. At location 2, we sampled in a sewer overflow at the overflow weir. Location 3 was a sewer by-pass in our experimental hall with a constant flow of real wastewater. Location 3 was also where the sampler uptake calibration experiment was performed [18]. Location 1 was equipped with a discharge measurement device (FloDar 4000SR). Additionally, the water level was measured (MB7369 HRXLMaxSonar-WRM) at locations 1 and 2. Three conditioned, replicate passive samplers (four replicate passive samplers at location 1) were exposed for the duration of the events, and four contaminants were studied (Table 1). Water samples were taken with automated sampling devices (Sigma 900MAX) every $5 \mathrm{~min}$, pooling four samples to a $20 \mathrm{~min}$ composite sample in a glass bottle (total 24 bottles). To enhance transparency of evaluation, we assumed that the concentration in composite samples $\mathrm{C}_{\text {Comp.Sample }}$ are equal to $\mathrm{C}_{\text {true. }}$. This simplification is discussed in Section 3.4.

Table 1. Studied contaminants with logKow, model parameters: instantaneous sampling rate $R s$ and sampler water distribution coefficient $\mathrm{K}_{S W}$ estimated for sewers (Eq.1).

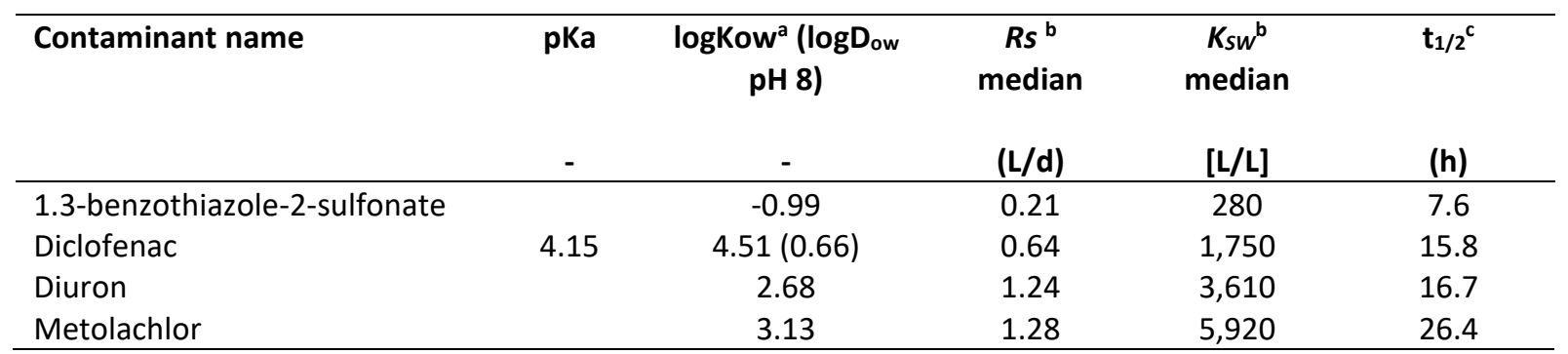

${ }^{\mathrm{a}} \mathrm{pKa}$ and experimental logKow were taken from www.pubchem.ncbi.nlm.nih.gov (accessed 01.03.2018). Distribution coefficients in brackets are normalized to the fraction of the neutral species at the $\mathrm{pH}$ of river water $(\mathrm{pH}=8), \mathrm{D}$ ow $(\mathrm{pH}$ $8)=1 /\left(1+10^{(8-p K a)}\right) K_{\text {ow }},{ }^{b}[18]$, ${ }^{c} E q .3$ in Section 2.2

\section{Preparation and extraction of passive sampler disks}

Before being exposed, styrene divinylbenzene passive samplers (Empore, SDB-RPS disks, $47 \mathrm{~mm}$ diameter) were preconditioned in methanol and in nanopure water [19]. The disks were exposed in a metal housing with an one-sided exposed surface area of $12.6 \mathrm{~cm}^{2}$ (Figure SI 1). After exposure, the whole disks were extracted with acetone and then methanol as described in [20]. Structure-identical isotope-labelled standards were added directly after shaking the disks with acetone on the rotary shaker to also account for possible analyte loss during sample preparation steps. Extracts were evaporated to ca. $0.05 \mathrm{~mL}$ and filled with nanopure water to $0.5 \mathrm{~mL}$. 


\section{Chemical Analysis}

All samples were stored at $-20^{\circ} \mathrm{C}$ until analysis. Water samples from locations 1 and 2 were measured with an online-SPE-ESI-LC-HRMS/MS system (QExactive by Thermo Fisher Scientific Corporation) using Huntscha et al.'s (2012) method [21]. Chromatographic separation was performed with a Water Atlantis T3 $(4.6 \times 150 \mathrm{~mm}, 3 \mu \mathrm{m}$ particle size). Data were generated in data-dependent mode. Water samples from location 3 were measured on an Agilent 6495 triple quad mass spectrometer using ESI. Chromatographic separation was performed with a Waters Acquity UPLC HSS T3 (3x100mm, $1.8 \mu \mathrm{m}$ particle size). Data acquisition was achieved in dynamic MRM mode. All passive sample extracts were directly injected $(100 \mu \mathrm{L})$ and measured on the QExactive using the same LC-MS conditions as for the water samples. Quantification was done using the internal standard method. Structure-identical isotopiclabelled standards were available for all compounds except 1,3-benzothiazole-2-sulfate. Here, Bezotriazole-D4 was used for quantification, and measured values were corrected by the relative recovery of this compound. Quality controls such as external reference standards, spiked samples for recoveries, blind, field blind controls, and filter blind controls were measured regularly during all measurement sequences. Further details on chemical analysis are given in SI Section C.

\subsection{Uncertainty due to fluctuating concentration patterns}

An exponential function is often used to describe the uptake of contaminant mass $\left(M_{P S}\right)$ on passive samplers (Eq. 1); here, $C_{i}$ is the concentration in the water phase at time point $i, V_{P S}$ the passive sampler volume $(344 \mu \mathrm{L}$ with $90 \%$ of the total mass as sorbent mass [22]), and $t$ the exposure duration.

$$
\frac{d M_{P S}}{d t}=R_{S}\left(C_{i}(t)-\frac{M_{P S}}{V_{P S} \cdot K_{S W}}\right)
$$

When $C i$ is constant, two main uptake phases can be distinguished: (i) an almost linear integrative phase, where uptake is mainly controlled by the sampling rate $R_{S}$, and (ii) an equilibrium phase, described by the sampler-water distribution coefficient $K_{S W}$ [e.g. 23]. Fluctuating concentrations complicate this picture, for example when aqueous concentrations suddenly drop after equilibrium has almost been reached. In such a case, desorption can occur due to a lower equilibrium. Figure 2 illustrates an extreme case for a compound with a low $\mathrm{t}_{1 / 2}$ of $5.7 \mathrm{~h}$. In sewers and rivers, several peaks with varying durations can occur during a monitoring period.

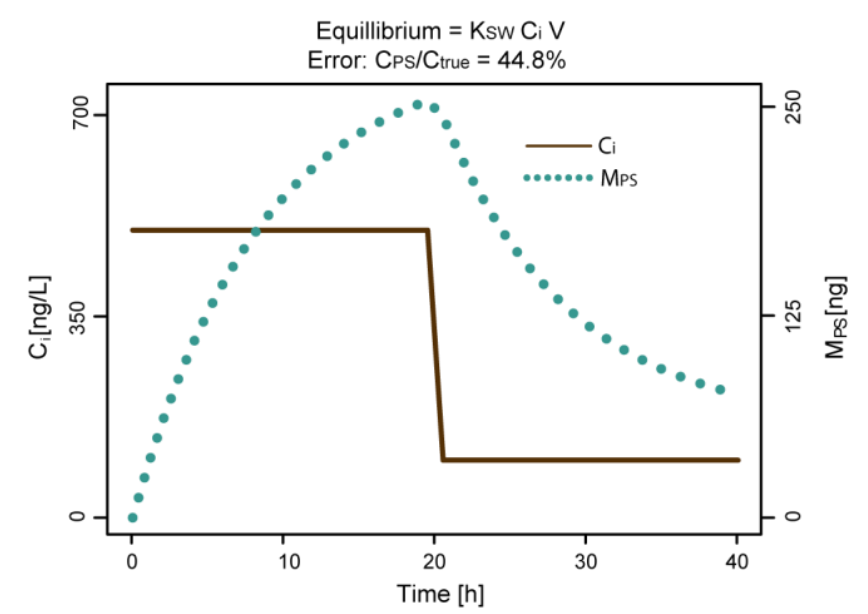

Figure 2. Example for an extreme case of equilibration and desorption on a passive sampler based on Eq. $1\left(K_{S W}=\right.$ $\left.1500, R_{S}=1.5 \mathrm{~L} / \mathrm{d}, \mathrm{t}_{1 / 2}=5.7 \mathrm{~h}\right)$. Mass on passive sampler $\mathrm{M}_{\mathrm{PS}}(\mathrm{t})$ showing desorption due to equilibration. Equilibrium 1 of $258 \mathrm{ng}$ during the first part with high concentrations and a lower equilibrium 2 of 52ng due to lower concentrations in the second half of the time series. This results in an underprediction of the TWA concentration $\mathrm{C}_{\mathrm{PS} \text {.mod }}$ in comparison to the true TWA concentration $\mathrm{C}_{\text {true }}$. 
Using measured or modelled concentration time series with known $\mathrm{C}_{\mathrm{i}}(\mathrm{t})$ as input for Eq. 1, we determine the theoretical mass modelled $\mathrm{M}_{\mathrm{PS} \text {.mod }}$ that should accumulate on the passive sampler, as shown in Figure 1. This MPS.mod allows the TWA concentration $\mathrm{C}_{\mathrm{PS} \text {.mod }}$ to be back-calculated (Eq.2). The comparison of this modelled passive sampler TWA concentration $\mathrm{C}_{\mathrm{PS}}$ with the true TWA water concentration $\mathrm{C}_{\text {true }}$ quantifies the error solely due to fluctuating concentrations (\#1 in Figure 1). In the following, we express this comparison as the ratio $\mathrm{C}_{\mathrm{PS}} / \mathrm{C}_{\text {true }}$ and give the $80 \%$ interquantile range unless otherwise stated. In addition, the error $\mathrm{C}_{\mathrm{PS} \text {.mod.lin }} / \mathrm{C}_{\text {true }}$ caused by neglecting desorption can be calculated by applying the linear model (Eq. 4).

$$
\begin{aligned}
& C_{P S}=\frac{M_{P S}}{V_{P S} \cdot K_{S W}\left(1-e^{-\left(\frac{R_{S}}{V_{P S} \cdot K_{S W}}\right) t}\right)} \\
& t_{\frac{1}{2}}=\frac{V_{P S} \cdot K_{S W}}{R_{S}} \ln (2) \\
& C_{P S . l i n}=\frac{M_{P S}}{R_{S} \cdot t}
\end{aligned}
$$

This evaluation of the uncertainty due to fluctuating concentrations can be applied to high-resolution concentration patterns, both measured (section 2.1/3.1) and modelled (see subsequently and 3.2). Model calculation was performed in $\mathrm{R}$ [24].

\section{Modelled concentration patterns for sewer overflows and rivers}

The concentration patterns measured in sewer overflows might only represent a few of the possible patterns. In contrast, modelled concentrations allow a higher number of observable patterns to be covered. In addition, we are able to extend our study to fluctuations in rivers. For sewer overflows, modelled mecoprop concentration patterns [25] were used to calculate $\mathrm{M}_{\mathrm{PS} \text { mod }}$ for each of 216,052 modelled events (10-minute resolution). Similarly, 2,199 modelled river concentrations interpolated to hourly resolution were used to estimate the ratio of $\mathrm{C}_{\mathrm{PS} \text {.mod }} / \mathrm{C}_{\text {true }}$ for six contaminants for which modelled data was available: diuron and atrazine at $10 \mathrm{~min}$ resolution for 7 months, atrazine at 20min resolution for 5 years [26, 27], and isoproturon, metolachlor, and terbutylazine at $1 \mathrm{~h}$ resolution in 12 locations for 1 year [28]. These modelled concentration patterns are potentially more representative for contaminants such as diuron and metolachlor that originate from surface runoff. This difference in contaminant behaviour is especially relevant for rivers, for which diclofenac is expected to display a more constant occurrence pattern. Further, the modelled concentration patterns rely on various model simplifications and thus cover only part of the complexity of contaminant release from many contributing sources. These modelled sewer overflow concentration patterns were applied to the four studied contaminants (Table 1). The periods of PS exposure considered were event-based, implying that $C_{P S}$ is evaluated over different durations (Table 2).

For rivers, an 'event' was defined as a 1-week deployment period, resulting in a constant evaluation interval ( $\mathrm{t}=7$ days). We looked at diuron and used instantaneous $R_{S}$ of $0.82 \mathrm{~L} / \mathrm{d}$ and $\mathrm{K}_{\mathrm{Sw}}$ of $27,000 \mathrm{~L} / \mathrm{L}$ reported in literature for naked SDB-RPS disks in river conditions [22, 29]. We used literature values instead of our own values to account for typically lower flow rates in rivers of 0.2 to $0.5 \mathrm{~m} / \mathrm{s}$. Flow rates are known to affect $R s$ [19].

\subsection{Pattern characteristics influencing deviations from true TWA concentration}

To investigate the effect of fluctuating patterns on the passive sampler concentration estimate $\mathrm{C}_{\mathrm{PS} \text {.mod, we }}$ characterize patterns with (i) the event length, in the case of event-based sewer overflow sampling; (ii) the 
fluctuation of the concentration described by the coefficient of variation $(\mathrm{CV}$, defined as the standard deviation divided by the mean); and (iii) the position of the peak described by the half-time ratio (htr). The htr was calculated as shown in Eq. 5 with $n$ as the total length of the time series (see Figure SI 7 for calculation example).

$h t r=-\log \left(\frac{\operatorname{sum}\left(C(t)_{1-n / 2}\right)}{\operatorname{sum}\left(C(t)_{n / 2+1-n}\right)}\right)$

These three characteristics were used to describe the three events measured at locations 1,2, and 3 and the modelled sewer overflow and river concentration patterns (Table 2).

Table 2. Characteristics of the measured and modelled high resolution concentration patterns for sewer and rivers. Values given in median ( $80 \%$ interquantile). Position of the peak (htr): A negative value signifies a peak in the beginning and a positive value a peak in the end. CS: composite sample, PS: passive sample

\begin{tabular}{lccc}
\hline & $\begin{array}{c}\text { Length } \\
\text { (h) }\end{array}$ & $\begin{array}{c}\text { CV } \\
\text { (\%) }\end{array}$ & $\begin{array}{c}\text { Position of peak } \\
(-)\end{array}$ \\
\hline Measured locations & & $60(44-120)$ & $-0.5(-1.1-0.3)$ \\
Location $1(18.05 .2016), \mathrm{v}=1.4 \mathrm{~m} / \mathrm{s}$ & 7.7 & & \\
Location 2 (25.04.2017), $\mathrm{v}=0.75 \mathrm{~m} / \mathrm{s}$ & $\mathrm{CS}: 7.7^{*}, \mathrm{PS}: 13.7$ & & \\
Location 3 (28.06.2017), $\mathrm{v}=0.8 \mathrm{~m} / \mathrm{s}$ & 8 & & $-0.007(-0.3-0.3)$ \\
Modelled sewer overflow pattern & $1.7(0.3-6.8)$ & $11(3-39)$ & $-0.003(-0.2-0.2)$ \\
\hline
\end{tabular}

*The automated water sampling only partly covered the whole event of $13.7 \mathrm{~h}$ (see Figure SI 4).

We hypothesize that (i) a shorter event duration results in a smaller error, due to not having reached equilibrium; (ii) a more fluctuating concentration (high CV) leads to a larger error due to a higher chance of desorption; and that (iii) a peak in the second half (positive htr value) leads to less desorption and thus a smaller error.

\subsection{Accuracy of composite samples}

As mentioned previously, the composite sample may not represent $\mathrm{C}_{\text {true. }}$. Therefore, we assess the effect of the time interval between samples collected for the composite sample, termed the sampling resolution, on the $\mathrm{C}_{\mathrm{TWA}}$ estimate from composite water samples for fluctuating concentrations. The uncertainty due to fluctuating concentrations in sewers during dry weather conditions has previously been studied by modelling grab sampling and predicting the error over a range of sampling time intervals [30]. The error from all potential sources of uncertainty (\#1-3 in Figure 1) was assessed using the field data for composite water sampling $\mathrm{C}_{\mathrm{CS} \text {.meas }}$ and passive sampler TWA concentration $\mathrm{C}_{\mathrm{PS} \text {.meas. }}$

\section{Results and discussion}

Section 3.1 describes the measured high-resolution concentration patterns and assesses the uncertainty expected from fluctuating concentrations alone (as in section 2.2). The uncertainty due to other factors (\#3 in Figure 1) is also assessed, since measurements for $M_{P S}$ are available. In section 3.2, the method described in section 2.2 is applied to the modelled concentration patterns. 


\subsection{Measured concentration patterns and expected uncertainty of time- weighted average concentration estimates due to fluctuating concentrations}

Twenty-minute composite samples collected at five-minute intervals reveal appreciable concentration fluctuations (Figure 3). The CVs of the 12 patterns range from $44 \%$ to $120 \%$, indicating high variability of concentrations across all events and contaminants (Table 2).
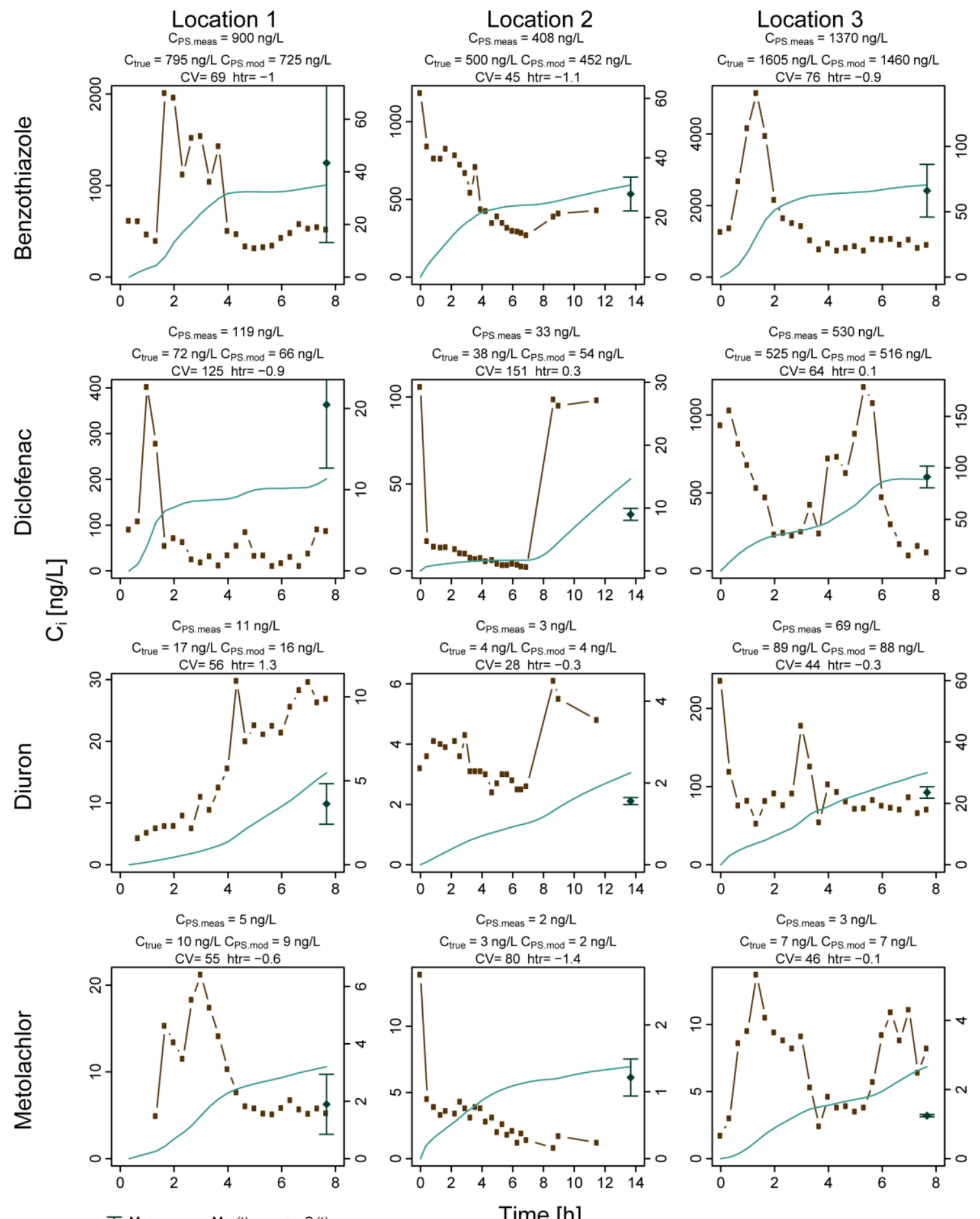

ㅍ MPS.meas $-M P S(t)_{\text {mod }} \rightarrow \mathrm{C}_{i}(\mathrm{t})_{\text {meas }}$

Time $[\mathrm{h}]$ 
Figure 3. Locations 1-3 measured with $20 \mathrm{~min}$ resolution (four samples, $\Delta \mathrm{t}=5 \mathrm{~min})$ composite samples $\left(\mathrm{C}_{\mathrm{i}}(\mathrm{t})\right.$ ): brown rectangles with solid line. Modelled mass on the disk (MPS.mod): solid green line. The mean measured mass on the passive samplers (MPS.meas) is shown with dark, green diamonds (whiskers show standard deviation; only partly shown if outside plotting range). The comparison of $\mathrm{C}_{\text {true }}$ with the modelled passive sampler $\mathrm{C}_{\mathrm{PS} \text {.mod }}$ covers the uncertainty due to fluctuating concentrations.

The interlocation (Figure 3) comparison shows high variability in concentration ranges for 1.3benzothiazole-2-sulfonate, diclofenac, and diuron. In general, no contaminant or location specific pattern is observable. Location 1 was a sewer with potentially less complex sources of contaminants (5.7ha of solely residential area and short transport times), the patterns seem to exhibit source-specific behaviour. Diclofenac shows a distinct peak at the beginning (negative htr), while elevated diuron values appear towards the end (positive htr value). These observed variations at location 1 can be explained by contaminant-specific occurrence in urban sources. Diclofenac occurs mainly in the wastewater base flow, and as the sampling started $80 \mathrm{~min}$ before elevated water levels were observed (see Figure SI 2), diclofenac is diluted during the actual surface runoff event. In contrast, 1.3-benzothiazole-2-suflonate, diuron and metolachlor are expected to be rain-driven and accordingly show a peak in location 1 as soon as the water level rises, indicating wash-off from surfaces. Interestingly, the diuron peak occurs very late and remains high over the last four hours of the event - this is hypothesized to be due to the runoff-driven, lagged wash-off behaviour of facades, the main source of diuron [7]. Although our 5-minute sampling regime is thought to capture all short-term peaks, the 20-minute compositing period might lead to attenuated peaks (section 3.4).

Table 3. Uncertainty (expressed as ratio) of the measured and modelled passive sampling TWA concentration estimate: overall contaminants together. The mean of the samplers was used for measured passive sampling concentration $\mathrm{CPS}_{\mathrm{PS} \text { meas. }}$

\begin{tabular}{|c|c|c|c|c|}
\hline & $\begin{array}{l}\text { Min } \\
(\%)\end{array}$ & $\begin{array}{c}\text { 10\%-quantile } \\
\text { (\%) }\end{array}$ & $\begin{array}{c}\text { 90\%-quantile } \\
\text { (\%) }\end{array}$ & $\begin{array}{l}\text { Max } \\
\text { (\%) }\end{array}$ \\
\hline \multicolumn{5}{|c|}{ Measured locations 1-3 } \\
\hline \multicolumn{5}{|c|}{ Uncertainty due to fluctuations ${ }^{\mathrm{a}}$ (\#1 in Figure 1 ) } \\
\hline \multicolumn{5}{|c|}{ Uncertainty due to other factors (\#3 in Figure 1 ) } \\
\hline$C_{P S \text {.meas }} / C_{P S \text {.mod }}$ & 47 & 59 & 120 & 180 \\
\hline \multicolumn{5}{|c|}{ Modelled sewer overflow pattern: Uncertainty due to fluctuations (\#1 in Figure 1 ) } \\
\hline$C_{\text {PS.mod }} / C_{\text {true }}$ & 27 & 99.5 & 100.4 & 170 \\
\hline CPS.mod.lin/ $/ C_{\text {true }}$ & 9 & 83 & 99 & 100 \\
\hline \multicolumn{5}{|c|}{ Modelled river pattern: Uncertainty due to fluctuations (\#1 in Figure 1) } \\
\hline$C_{P S \text { mod }} / C_{\text {true }}{ }^{b}$ & 74 & 97 & 102 & 127 \\
\hline
\end{tabular}

If the differences observed between passive sampling and composite water sampling in Figure 3 could be explained by the fluctuating concentration patterns, one would expect to observe values for $\mathrm{C}_{\mathrm{PS} \text { meas }}$ that do not deviate more than $-13 \%$ to $+40 \%$ from the theoretical $\mathrm{C}_{\mathrm{PS} \text {.mod }}$ (Table 3). $\mathrm{C}_{\mathrm{PS} \text {.mod }}$ is determined from the measured high-resolution concentration $\mathrm{Ci}(\mathrm{t})$ and incorporates all desorption effects. However, we find that the uncertainty attributed to other factors, expressed by the ratio $\mathrm{C}_{\mathrm{PS} \text {.meas }} / \mathrm{C}_{\mathrm{PS} \text {.mod, }}$, ranges from $47 \%$ (metolachlor) to $180 \%$ (diclofenac); this clearly exceeds the uncertainty caused solely by fluctuating concentrations.

The measured $\mathrm{C}_{\mathrm{PS} \text {.meas }}$ is lower than the theoretical $\mathrm{C}_{\mathrm{PS} \text {.mod }}$ for diuron $(66 \%, 70 \%, 79 \%)$ and metolachlor $(59 \%, 88 \%, 47 \%)$ in all three locations (Figure 3). Hence, this observed underestimation for diuron and metolachlor cannot be attributed to fluctuating concentrations either (ratio $\mathrm{C}_{\mathrm{PS} \text {.mod }} / \mathrm{C}_{\text {true }}$ of diuron: $97 \%$, $106 \%, 98 \%$ and metolachlor: $89 \%, 86 \%, 100 \%$ ). 


\subsection{Uncertainty of time-weighted average concentration estimates due to fluctuating concentrations for modelled concentration patterns}

In this section, the pattern-specific, modelled $\mathrm{C}_{\mathrm{PS} \text {.mod }}$ is compared to $\mathrm{C}_{\text {true }}$ to exclude other influencing uncertainty factors such as sampler set-up, chemical analysis, and calculation of water concentration. Passive sampling of sewer overflows shows a ratio $\mathrm{C}_{\mathrm{PS} \text { mod }} / \mathrm{C}_{\text {true }}$ of minimum $27 \%$ to maximum $170 \%$ (80\%-interquantile $99.5-100.4 \%$, Table 3). Nevertheless, in the majority of modelled sewer overflow event patterns, the deviation is smaller $<0.5 \%$ for all four contaminants (Figure 4).



Figure 4. Predicted contaminant-specific ratios of $\mathrm{C}_{P S \text {.mod }} / \mathrm{C}_{\text {true }}$ for the modelled sewer overflow concentration pattern. Outliers are not shown; the whiskers show $1.5 \times$ interquartile range. Contaminants are sorted top to bottom from high to low $\mathrm{t}_{1 / 2}$.

The modelled sewer overflow event patterns span $80 \%$ interquantile CVs of $3 \%$ to $39 \%$. This is lower than for the twelve measured patterns, which had CVs of $44 \%$ to $120 \%$ (Table 2). This indicates the complexity of considering all contaminant sources and potential spills in model predictions of fluctuating concentrations.

Overall, the modelled uncertainty due to fluctations is small. The three measured events span a ratio of $\mathrm{C}_{\mathrm{PS} . \bmod } / \mathrm{C}_{\text {true }}$ of $89 \%$ to $105 \%$ due to fluctuations, which is higher than for the modelled patterns of $99.5 \%$ to $100.4 \%$ ( $80 \%$ interquantile). The modelled concentration patterns cover a high number of sewer overflow locations and rain events but do not specifically reflect the three sampling locations. This indicates that the extreme cases are more common than the modelled pattern indicates.

\section{The effects of $\boldsymbol{R}_{S}$ and $\boldsymbol{K}_{S W}$ and the integrative model approach}

The contaminant-specific model parameters for sampling rate, $R s$, and sampler-water distribution coefficient, $K_{S W}$, can cause the predicted ratio of $\mathrm{C}_{\mathrm{PS} \text { mod }} / \mathrm{C}_{\text {true }}$ to increase; this is the case for 1.3benzothiazole-2-sulfonate. A higher sampling rate, $R s$ and a lower $K_{S W}$ both result in equilibrium being reached more quickly, and thus the deviation of $\mathrm{C}_{\mathrm{PS} \text {.mod }}$ from $\mathrm{C}_{\text {true }}$ increases.

Applying the solely integrative model with instantaneous $R s$ to the sampling of sewer overflows leads to a ratio $\mathrm{C}_{\mathrm{PS} \text {.mod.lin }} / \mathrm{C}_{\text {true }}$ ranging from $83 \%$ to $99 \%$ (median $96.4 \%$ ). This range is substantially broader than that predicted for the full model: $99.5 \%$ to $100.4 \%$. The integrative model thus leads to higher deviations when calculating $\mathrm{C}_{\mathrm{PS} \text {.mod }}$ using Eq. 4, as many events are affected by equilibrium issues: peak concentrations followed by low concentrations, which can cause desorption. This shows that using the full model is the preferred option, because it produces results that are either comparable with the integrative model in the linear phase or more accurate when intermediate sampling phases occur. Technically, the full model is not more difficult to implement.

\subsection{Pattern characteristics influencing deviations from true TWA concentration}

As hypothesized, we find that the characteristics of the fluctuating concentrations influence the magnitude of the deviation of $\mathrm{C}_{\mathrm{PS} \text {.mod }}$ from $\mathrm{C}_{\text {true. }}$. Figure 5 shows this ratio for all modelled sewer patterns in relation 
to event length, $\mathrm{CV}$, and position of the peaks for diclofenac and metolachlor (1.3-benzothiazole-2sufonate and diuron are shown in Figure SI 8). Each grey dot reflects the uncertainty $\mathrm{C}_{\mathrm{PS} \text {.mod }} / \mathrm{C}_{\text {true }}$ due to concentration fluctuations for a single modelled concentrations pattern. The longer the event length is, the higher is the ratio of $\mathrm{C}_{\mathrm{PS} \text {.mod }} / \mathrm{C}_{\text {true }}$, as shown by the $10 \%$ and $90 \%$ quantile regression lines (Figure 5, left). The same applies for the concentration variability: the larger the $\mathrm{CVs}$ are, the more $\mathrm{C}_{\mathrm{PS} \text {.mod }}$ deviates from $\mathrm{C}_{\text {true }}$ (Figure 5, middle).

The effect of the position of the peak can be seen in Figure 5, right. A positive htr, indicating a peak at the end, leads to an overestimation of $\mathrm{C}_{\text {true }}$, whereas a negative htr, indicating a peak at the beginning, leads to an underestimation of $\mathrm{C}_{\text {true. }}$. In summary, the absolute deviation from $\mathrm{C}_{\text {true }}$ depends strongly on the specific pattern characteristics. A further extreme case with very low $\mathrm{K}_{\mathrm{Sw}}$ for the position of the peak is shown in Figure SI 9.

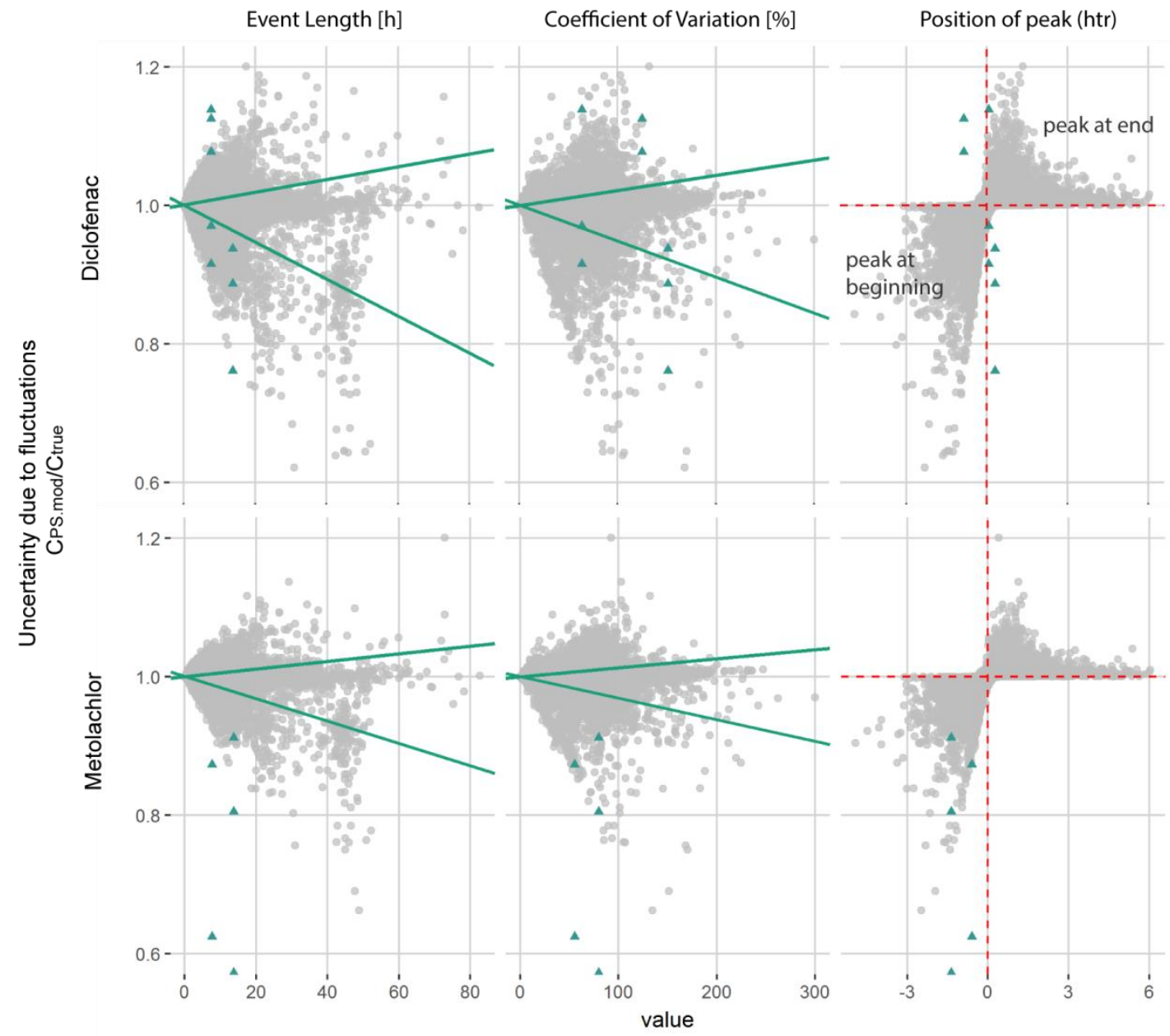

Figure 5. Predicted uncertainty due to fluctuating concentration $C_{P S \text { mod }} / C_{\text {true }}$ for the modelled sewer concentration pattern (half-transparent grey point) in relation to event length [h], coefficient of variation (CV in \%), and position of the peak (htr). The $10 \%$ and $90 \%$ quantile regressions are shown by the green solid lines; red dashed lines show htr $=0$ and $\mathrm{C}_{\mathrm{PS} . \bmod } / \mathrm{C}_{\text {true }}=1$. For comparison, the overall uncertainty (green triangles) of the measured passive sampling $\mathrm{C}_{\mathrm{PS} \text {.meas }} / \mathrm{C}_{\text {Comp.Sample }}$ of locations 1-3 is shown.

Looking at the overall measured uncertainty of the ratio $\mathrm{C}_{\mathrm{PS} \text {.meas }} / \mathrm{C}_{\mathrm{Comp.Sample}}$ in relation to event length and $\mathrm{CV}$, the ratios for metolachlor lie outside the quantile regression lines (Figure 5, left and middle). The observed underestimation of metolachlor cannot be explained by either the event length or the CV. In the case of diclofenac, the observed deviation lies within the extreme cases, and thus part of the deviation can be explained by the observed event-specific pattern. Interestingly, the position of the peak does not seem to be a good predictor of underestimation or overestimation for some of the contaminants, as seen for diclofenac (Figure 5, right). 
In summary, the overall uncertainty, expressed as the ratio of $\mathrm{C}_{\mathrm{PS} . m e a s} / \mathrm{C}_{\text {Comp.Sample, }}$, ranges from minimum $47 \%$ to maximum $165 \%$ for sewers (Table 4), and the mean reported ratios for rivers range from $50 \%$ (Shaw and Mueller, 2009) to 260\% (Fernandez et al. 2014). These can only partly be explained by the fluctuating concentrations that typically occur in sewers and river streams. The observed experimental and analytical parameter uncertainty and the uncertainty due to variable environmental conditions indicate similar or even higher uncertainty ranges. In addition, part of the difference observed between passive sampling and composite water sampling can be attributed to uncertainties associated with the water sampling regime $\left(\mathrm{C}_{\text {Comp.Sample }}\right)$. The water sampling regime often does not cover the full concentration variability, and thus can lead to unrepresentative TWA concentration estimates. Therefore, when comparing passive sampling $\mathrm{C}_{\mathrm{PS} \text {.meas }}$ with active sampling $\mathrm{C}_{\text {Comp.Sample }}$, it should also be considered that the measured $\mathrm{C}_{\text {Comp.Sample }}$ may not represent $\mathrm{C}_{\text {true }}$ (section 3.4).

\subsection{Accuracy of composite samples}

Fluctuating concentrations and other factors imply that both $\mathrm{C}_{\mathrm{PS} \text {.meas }}$ and $\mathrm{C}_{\text {Comp.Sample }}$ are only approximations of $\mathrm{C}_{\text {true. }}$. The question arising is how accurate passive sampling is in comparison to highresolution grab sampling, leaving aside other influencing factors such as sample preparation, accuracy and precision of chemical analyses, and passive sampler calibration. $\mathrm{C}_{\text {Comp.Sample }}$ can deviate from $\mathrm{C}_{\text {true }}$ due to (i) the sampling resolution, how often a sample is taken to form a composite sample over the entire period, and (ii) the time span that the composite sample covers. For composite sampling of sewer overflows, the ratio $\mathrm{C}_{\text {Comp.Sample }} / \mathrm{C}_{\text {true }}$ is between $98 \%$ to $102 \%$ for 15 -min sampling intervals and $86 \%$ to $110 \%$ for 120 min sampling intervals. To be in the same uncertainty range as modelled for passive sampling $\left(\mathrm{C}_{\mathrm{PS} \text {.mod }} / \mathrm{C}_{\text {true }}\right.$ of $99.5 \%$ to $100.3 \%$ ), then, sampling intervals should not exceed $15 \mathrm{~min}$. However, the measured concentration patterns indicate a higher concentration variability than the modelled patterns (Section 3.2), so sampling intervals $<10 \mathrm{~min}$ are recommended.

Table 4. Uncertainty, expressed as ratio, of the composite water TWA concentration estimate for the modelled pattern (uncertainty due to fluctuations, \#1 in Figure 1) and measured overall uncertainty (\#1-3 in Figure 1).

\begin{tabular}{|c|c|c|c|c|}
\hline & $\begin{array}{l}\text { Min } \\
(\%)\end{array}$ & $\begin{array}{c}10 \% \text {-quantile } \\
\text { (\%) }\end{array}$ & $\begin{array}{c}\text { 90\%-quantile } \\
\text { (\%) }\end{array}$ & $\begin{array}{l}\text { Max } \\
(\%)\end{array}$ \\
\hline \multicolumn{5}{|c|}{ Measured locations 1-3: Overall uncertainty (\#1-3 in Figure 1) } \\
\hline CPS.meas/CComp.Sample.meas & 47 & 54 & 110 & 165 \\
\hline \multicolumn{5}{|c|}{ Modelled sewer overflow pattern: Uncertainty due to fluctuations (\#1 in Figure 1) } \\
\hline Comp.Sample $/ C_{\text {true }} \Delta \mathrm{t}=15 \mathrm{~min}$ & 28 & 98 & 102 & 160 \\
\hline$C_{\text {Comp.Sample }} / C_{\text {true }} \Delta t=120 \mathrm{~min}$ & 1.3 & 86 & 110 & 590 \\
\hline \multicolumn{5}{|c|}{ Modelled river pattern: Uncertainty due to fluctuations ( $\# 1$ in Figure 1 ) } \\
\hline $\mathrm{C}_{\text {comp.sample }} / \mathrm{C}_{\text {true }} \Delta \mathrm{t}=48 \mathrm{~h}$ & 0.001 & 94 & 106 & 510 \\
\hline $\mathrm{C}_{\text {comp.sample }} / \mathrm{C}_{\text {true }} \Delta \mathrm{t}=12 \mathrm{~h}$ for $\mathrm{CV}>20 \%$ & 27 & 88 & 105 & 270 \\
\hline
\end{tabular}

${ }^{\mathrm{a}}$ Without benzotriazole values from location 2 and 3

\subsection{Surface waters: Uncertainty due to fluctuating concentrations for modelled concentration patterns}

For diuron, the uncertainty due to fluctuating concentrations $\mathrm{C}_{\mathrm{PS} \text {.mod }} / \mathrm{C}_{\text {true }}$ ranges from $97 \%$ to $102 \%$ (Table 3). The slightly higher ratio of $\mathrm{C}_{\mathrm{PS} \text {.mod }} / \mathrm{C}_{\text {true }}$ for river sampling than for sewer sampling can be explained by the sampling duration of a week, which is in a similar range as the reported $t_{1 / 2}$ of 7.9 days. The predicted uncertainty due to fluctuations will also increase for other contaminants with lower $\mathrm{t}_{1 / 2}$ values. In rivers, longer periods with low concentrations can occur during dry weather, so desorption may affect $\mathrm{C}_{\mathrm{PS} \text {.mod }}$ more than with sampling in sewers. 
One-week composite sampling of rivers taking a sample every second day (based on concentration resolution of one hour) leads to an estimated ratio $\mathrm{C}_{\text {Ccomp.Sample }} / \mathrm{C}_{\text {true }}$ of $94 \%$ to $106 \%$ (Table 4 ). The predicted ratio for passive samplers of $\mathrm{C}_{\text {PS.mod }} / \mathrm{C}_{\text {true }}$ for diuron in rivers of $97 \%$ to $102 \%$ is in a similar range. A grab sample every second day might be an appropriate sampling scheme for baseline concentrations. For concentration peaks that might pose a higher eco-toxicological risk for aquatic organisms, the extreme cases with higher peaks are of interest. Therefore, we looked at a subset of the data in which CVs were higher than the mean of $20 \%$, resulting in 455 concentration patterns (1-week sampling). Here we find that a sample every $12 \mathrm{~h}$ or more frequent would be required to bring the deviation into the same range as predicted for passive samplers.

\section{Conclusions}

The theoretical effects of integrative sampler uptake and desorption for simple cases is well understood. However, the extent to which unknown, complex fluctuations in concentration affect the estimation of TWA concentrations is less obvious. We find evidence that concentration fluctuations in sewers cannot explain the overall observed difference between measured passive sampler and composite water sample TWA concentrations. Using a high number of modelled patterns, we find that the effect of fluctuating concentrations on the TWA concentration estimate from passive samplers is small $(<1 \%$ for sewer sampling and $<3 \%$ for one-weekly river sampling). For our scenarios, we find low uncertainties associated with fluctuating concentrations, provided that the sampler operates in integrative mode (i.e., event durations do not substantially exceed $\mathrm{t}_{1 / 2}$ ) and calibration is appropriate for environmental conditions. Our results clearly show that uncertainty increases with higher event duration or an early or late peak. In general, the calibrated full-uptake model leads to more reliable results across variable sampling durations and for fluctuating concentrations. By extending the integrative phase, for instance by mounting a membrane, sampling uncertainty in rivers could be further reduced, depending on the sampling duration. However, the effect of uptake lag would have to be studied. The transferability of our finding to other contaminants depends strongly on contaminant properties and behaviour in aquatic systems.

In summary, we find indication that the uncertainty due to fluctuating concentrations is small, with a maximum range of $87 \%$ to $140 \%$ for the measured sewer locations. Other factors such as matrix, environmental conditions, and chemical analysis have a similar or even higher impact on concentration estimates. The effect of the matrix on contaminant uptake needs to be studied in more detail. We conclude that passive samplers seem to provide useful concentration estimates for wet-weather events in wastewater systems with substantial short-term concentration fluctuations.

\section{Acknowledgements}

The authors thank the Swiss Federal Office for the Environment for funding (contract nr. 09.0033.PJ/J4051714). We are very thankful for the support during field work (Simon Dicht, Eawag, SWW) and for chemical analyses (Heinz Singer, Simon Mangold, and Philipp Longree, Eawag, Uchem) and gratefully acknowledge Mariane Schneider (Eawag, SWW) for her valuable comments on the manuscript. 


\section{References}

[1] A. Musolff, S. Leschik, F. Reinstorf, G. Strauch, M. Schirmer, Micropollutant Loads in the Urban Water Cycle, Environmental Science \& Technology, 44 (2010) 4877-4883.

[2] P.J. Phillips, A.T. Chalmers, J.L. Gray, D.W. Kolpin, W.T. Foreman, G.R. Wall, Combined sewer overflows: An environmental source of hormones and wastewater micropollutants, Environmental Science and Technology, 46 (2012) 5336-5343.

[3] C. Moschet, I. Wittmer, J. Simovic, M. Junghans, A. Piazzoli, H. Singer, C. Stamm, C. Leu, J. Hollender, How a Complete Pesticide Screening Changes the Assessment of Surface Water Quality, Environmental Science \& Technology, 48 (2014) 5423-5432.

[4] M.A. Rippy, A. Deletic, J. Black, R. Aryal, J.L. Lampard, J.Y. Tang, D. McCarthy, P. Kolotelo, J. Sidhu, W. Gernjak, Pesticide occurrence and spatio-temporal variability in urban run-off across Australia, Water research, 115 (2017) 245-255.

[5] A.J. Novic, D.S. O’Brien, S.L. Kaserzon, D.W. Hawker, S.E. Lewis, J.F. Mueller, Monitoring Herbicide Concentrations and Loads during a Flood Event: A Comparison of Grab Sampling with Passive Sampling, Environmental Science \& Technology, 51 (2017) 3880-3891.

[6] T. Doppler, A. Lück, L. Camenzuli, M. Krauss, C. Stamm, Critical source areas for herbicides can change location depending on rain events, Agriculture, Ecosystems \& Environment, 192 (2014) 85-94.

[7] I.K. Wittmer, H.P. Bader, R. Scheidegger, H. Singer, A. Luck, I. Hanke, C. Carlsson, C. Stamm, Significance of urban and agricultural land use for biocide and pesticide dynamics in surface waters, Water research, 44 (2010) 2850-2862.

[8] B. Vrana, F. Smedes, R. Prokeš, R. Loos, N. Mazzella, C. Miege, H. Budzinski, E. Vermeirssen, T. Ocelka, A. Gravell, S. Kaserzon, An interlaboratory study on passive sampling of emerging water pollutants, TrAC Trends in Analytical Chemistry, 76 (2016) 153-165.

[9] J.N. Huckins, J.D. Petty, J.A. Lebo, F.V. Almeida, K. Booij, D.A. Alvarez, W.L. Cranor, R.C. Clark, B.B. Mogensen, Development of the Permeability/Performance Reference Compound Approach for In Situ Calibration of Semipermeable Membrane Devices, Environmental Science \& Technology, 36 (2002) 85-91.

[10] I.J. Allan, J. Knutsson, N. Guigues, G.A. Mills, A.M. Fouillac, R. Greenwood, Evaluation of the Chemcatcher and DGT passive samplers for monitoring metals with highly fluctuating water concentrations, J Environ Monit, 9 (2007) 672-681.

[11] M. Shaw, J.F. Mueller, Time Integrative Passive Sampling: How Well Do Chemcatchers

Integrate Fluctuating Pollutant Concentrations?, Environmental Science \& Technology, 43 (2009) 14431448 .

[12] A. Skodova, R. Prokes, Z. Simek, B. Vrana, In situ calibration of three passive samplers for the monitoring of steroid hormones in wastewater, Talanta, 161 (2016) 405-412.

[13] H. Birch, A.K. Sharma, L. Vezzaro, H.C.H. Lützhøft, P.S. Mikkelsen, Velocity dependent passive sampling for monitoring of micropollutants in dynamic stormwater discharges, Environmental Science and Technology, 47 (2013) 12958-12965.

[14] D. Fernandez, E.L. Vermeirssen, N. Bandow, K. Munoz, R.B. Schafer, Calibration and field application of passive sampling for episodic exposure to polar organic pesticides in streams, Environmental pollution, 194 (2014) 196-202. 
[15] R.W. Gale, Three-compartment model for contaminant accumulation by semipermeable membrane devices, Environmental Science and Technology, 32 (1998) 2292-2300.

[16] S.A. Morrison, B. Luttbeg, J.B. Belden, Comparisons of discrete and integrative sampling accuracy in estimating pulsed aquatic exposures, Environmental pollution, 218 (2016) 749-756.

[17] D.W. Hawker, Modeling the response of passive samplers to varying ambient fluid concentrations of organic contaminants, Environ Toxicol Chem, 29 (2010) 591-596.

[18] L. Mutzner, S. Mangold, M. Maurer, A. Scheidegger, H. Singer, E. Vermeirssen, C. Ort, Passive sampling: An efficient way to monitor micropollutants in sewer overflows?, in: 14th IWA/IAHR International Conference on Urban Drainage, Prague, Czech Republic. https://www.dora.lib4ri.ch/eawag/islandora/object/eawag:17035, 2017, pp. 10-17.

[19] E.L. Vermeirssen, N. Bramaz, J. Hollender, H. Singer, B.I. Escher, Passive sampling combined with ecotoxicological and chemical analysis of pharmaceuticals and biocides - evaluation of three Chemcatcher configurations, Water research, 43 (2009) 903-914.

[20] E.L. Vermeirssen, C. Dietschweiler, B.I. Escher, J. van der Voet, J. Hollender, Uptake and release kinetics of 22 polar organic chemicals in the Chemcatcher passive sampler, Analytical and bioanalytical chemistry, 405 (2013) 5225-5236.

[21] S. Huntscha, H.P. Singer, C.S. McArdell, C.E. Frank, J. Hollender, Multiresidue analysis of 88 polar organic micropollutants in ground, surface and wastewater using online mixed-bed multilayer solid-phase extraction coupled to high performance liquid chromatography-tandem mass spectrometry, Journal of Chromatography A, 1268 (2012) 74-83.

[22] B.S. Stephens, A. Kapernick, G. Eaglesham, J. Mueller, Aquatic Passive Sampling of Herbicides on Naked Particle Loaded Membranes: Accelerated Measurement and Empirical Estimation of Kinetic Parameters, Environmental Science \& Technology, 39 (2005) 8891-8897.

[23] K. Booij, B. Vrana, J.N. Huckins, Chapter 7: Theory, modelling and calibration of passive samplers used in water monitoring., Elsevier, Amsterdam, 2007.

[24] R Core Team, R: A Language and Environment for Statistical Computing, in, R Foundation for Statistical Computing, http://www.R-project.org, Vienna, 2010.

[25] L. Mutzner, P. Staufer, C. Ort, Model-based screening for critical wet-weather discharges related to micropollutants from urban areas, Water research, 104 (2016) 547-557.

[26] I.K. Wittmer, H.P. Bader, R. Scheidegger, C. Stamm, REXPO: A catchment model designed to understand and simulate the loss dynamics of plant protection products and biocides from agricultural and urban areas, Journal of Hydrology, 533 (2016) 486-514.

[27] C. Stamm, S. R., J. Van der Voet, H. Singer, H.P. Bader, Organische Spurenstoffe im Rahmen von NADUF. Machbarkeitsstudie - Schlussbericht Studie im Auftrag des BAFU (ENG: organic micropollutants in the NADUF study - final report), in, Eawag, Dübendorf, 2011.

[28] A. Moser, D. Wemyss, R. Scheidegger, F. Fenicia, M. Honti, C. Stamm, Modelling biocide and herbicide concentrations in catchments of the Rhine basin, Hydrol. Earth Syst. Sci. Discuss., 2017 (2017) $1-36$.

[29] B.S. Stephens, A.P. Kapernick, G. Eaglesham, J.F. Mueller, Event monitoring of herbicides with naked and membrane-covered Empore disk integrative passive sampling devices, Marine Pollution Bulletin, 58 (2009) 1116-1122. 
[30] C. Ort, M.G. Lawrence, J. Reungoat, J.F. Mueller, Sampling for PPCPs in wastewater systems: Comparison of different sampling modes and optimization strategies, Environmental Science and Technology, 44 (2010) 6289-6296. 